\title{
The Effect of Extracorporeal Shock Wave Therapy on Myofascial Pain Syndrome
}

\author{
Jong Hyun Jeon, M.D., Yun Jae Jung, M.D., Ju Youn Lee, M.D., Ji Soo Choi, M.D., Jeong Hyeon Mun, M.D., \\ Won Yong Park, M.D., Cheong Hoon Seo, M.D., Ki Un Jang, M.D., Ph.D \\ Department of Rehabilitation Medicine, Hallym University Burn Institute, \\ Hallym University College of Medicine, Seoul 150-719, Korea
}

\begin{abstract}
Objective To investigate the effect of extracorporeal shock wave therapy (ESWT) on myofascial pain syndrome (MPS).

Method Thirty patients with MPS in trapezius muscle were randomly divided into two groups, ESWT group (n=15), and trigger point injections (TPI)+transcutaneous electrical nerve stimulation (TENS) group ( $\mathrm{n}=15)$. For a total of 3 weeks, ESWT was undertaken with 1,500 pulse each time at one week interval totaling 4,500 pulse, TPI for once a week totaling three times and TENS for five times a week totaling three weeks.

Results The changes in pain threshold $\left(\mathrm{lb} / \mathrm{cm}^{2}\right)$ showed the values of $6.86 \pm 1.35$ before first therapy, $11.43 \pm 0.27$ after first therapy, and $12.57 \pm 0.72$ after third therapy, while TPI+TENS group showed the values of $6.20 \pm 1.92$ before first therapy, $8.80 \pm 0.48$ after first therapy, and $9.60 \pm 2.19$ after third therapy, and the changes between the groups were significantly different ( $\mathrm{p}=0.045$ ). The changes in visual analog scale were estimated to be $6.86 \pm 0.90$ before first therapy, $2.86 \pm 0.90$ after first therapy, and $1.86 \pm 0.69$ after third therapy in case of ESWT group, whereas the figures were estimated to be $7.20 \pm 1.30$ before first therapy, $4.60 \pm 0.55$ after first therapy, and $2.80 \pm 0.84$ after third therapy in case of TPI+TENS group, and the changes between the groups were significantly different $(\mathrm{p}=0.010)$. The changes in McGill pain questionnaire $(\mathrm{p}=0.816)$ and pain rating scale $(\mathrm{p}=0.644)$ between the groups were not significantly different. The changes in neck ROM were also not significantly different between the groups $(\mathrm{p}>0.05)$. Conclusion The ESWT in patients with MPS in trapezius muscle are as effective as TPI and TENS for the purpose of pain relief and improving cervical range of motion.
\end{abstract}

Key Words Myofascial pain syndromes, High-energy shock waves, Trigger points, Pain threshold

Received March 26, 2012; Accepted July 13, 2012

Corresponding author: Ki Un Jang

Department of Rehabilitation Medicine, Hallym University Burn Institute, Hallym University College of Medicine, Yeongdeungpo-dong 2-ga, Yeongdeungpo-gu, Seoul 150-719, Korea

Tel: +82-2-2639-5730, Fax: +82-2-2633-7571, E-mail: jangkiun@hanmail. net

(c) This is an open-access article distributed under the terms of the Creative Commons Attribution Non-Commercial License (http:// creativecommons.org/licenses/by-nc/3.0) which permits unrestricted noncommercial use, distribution, and reproduction in any medium, provided the original work is properly cited.

Copyright $\odot 2012$ by Korean Academy of Rehabilitation Medicine

\section{INTRODUCTION}

Myofascial pain syndrome is known to be a clinically common syndrome with characteristics including localized muscle tenderness, typical referred pain, palpable intramuscular taut band and muscular twitching response, etc., and induction of pain due to the myofascial trigger points (MTrPs) is defined as hyperirritable spot of taut band.

Myofascial pain syndrome is a problem frequently ex- 
perienced in clinical setting that accounts for the largest proportion of the diseases of musculoskeletal system occurring in cervical and lumbar vertebral portion, and shoulder, and is a common cause that induces disability due to pain. The basic diagnostic method of myofascial pain syndrome is determined by physical examination such as localized muscle tenderness, typical referred pain, palpable intramuscular taut band, muscular twitching response along with subjective symptoms of the patients. In addition, method of assessment of pain threshold using algometry can be helpful in diagnosing myofascial pain syndrome. As the methods of treatment for myofascial pain syndrome, stretching, dry-needling and trigger point injection using diverse range of drugs are used along with generally practiced physical therapy. ${ }^{1}$

Recently, application of Extracorporeal Shock Wave Therapy (ESWT) has been expanded as one of the treatment methods for the diseases of musculoskeletal system. Although there have been reports about the effectiveness of ESWT mainly on epicondylitis, plantar fasciitis, chronic pelvic pain, chronic painful heel syndrome, lymphedema, burn wound, pressure ulcer and calcific tendinitis, its effectiveness on treatment of myofascial pain syndrome has not been reported. Accordingly, this study aims to examine the effectiveness and clinical usefulness of ESWT by comparing the ESWT implemented group with the trigger point injection (TPI) and transcutaneous electrical nerve stimulation (TENS) implemented group with myofascial pain syndrome patients as the subjects.

\section{MATERIALS AND METHODS}

The authors selected 30 patients who were diagnosed with myofascial pain syndrome in the trapezius muscle as a result of physical examination with pain in the posterior neck and shoulder areas as the chief complaint among the hospitalized patients at our hospital from January to December 2011 as the subjects of this study. This study is a prospective randomized experimental and control group research with the subjects divided into 2 groups, namely, the experimental group with 15 subjects who underwent ESWT, and the control group with 15 subjects who underwent TPI and TENS. For ESWT treatment, subjects were given total of 1,500 shock waves for each treatment at the rate of 240 waves, each with low en- ergy flux density (EFD) of $0.10 \mathrm{~mJ} / \mathrm{mm}^{2}$ per minute by using EvoTron RFL0300 of SwiTech Medical AG 3 times with a week's interval between the treatments (total of 4,500 shock waves). Treatment was given by focusing on the area at which muscular twitching response or referred pain should be induced by appropriately adjusting the location of the localized probe. Total of 3 TPI treatments with a week's interval between the treatment and total of 5 TENS treatments were given 5 times in a week with a duration of 20 minutes a day. Both the groups underwent treatment for total of 3 weeks each. Visual Analogue Scale (VAS), McGill pain questionnaire, Pain Rating Scale (PRS), neck range of motion (curvature, extension, rotation, lateral bending) and BASELINE ${ }^{\circledR}$ (Hoggan Health Industries Inc., West Jordan, USA) were used to confirm the changes in the pain threshold level $\left(\mathrm{lb} / \mathrm{cm}^{2}\right)$ prior to the first treatment (preliminary assessment), 1 week after the first treatment (interim assessment) and 1 week after the third treatment (final assessment) as the assessment method for assessing the effectiveness of treatment. At the time of final assessment, the results were categorized on the basis of assessment of Roles and Maudsley score and whether MTrPs was induced and referred pain was extinct, 'Excellent' if both have been extinct, 'Good' if only one of the 2 has been extinct and 'Poor' if both have not been extinct for additional execution of final response assessment.

Collected data were analyzed by using SPSS 19.0 program (SPSS Inc., Chicago, USA). Fisher's Exact test and Mann-Whitney test were carried out for homogeneity test on the 2 groups. Since the result of review of the normality assumption on the preliminary assessment tools of the 2 groups was satisfactory, Independent Samples t-Test was carried out to verify the preliminary homogeneity, and Repeated Measure ANOVA was carried out for examination of the effectiveness of the results of preliminary assessment, and assessment following the 1st and the 3rd treatment. Prior to execution of Repeated Measure ANOVA, Sphericity test of Mauchly for measurement of homoscedasticity and compound symmetry was performed. In the case of satisfaction of the sphericity assumption ( $>0.05$ ), verification of time effect (Time) and reciprocal action effect (Group $\times$ Time) were analyzed by using sphericity assumption statistics of Univariate test. If sphericity assumption was not satisfied ( $\mathrm{p}<0.05)$, statistics of Wilks' Lambda in Multivariate test was used. Moreover, Fisher's 
exact test of small specimen was carried out for verification of the results of Roles and Maudsley score and final response assessment. Lastly, in order to find out if there are differences in the results of treatment between the 2 groups due to gender difference, gender difference was confirmed by using Independent Samples t-Test in the final assessment.

\section{RESULTS}

Demographic and clinical characteristics of the patients A total of 30 patients comprised 22 males and 8 females. Of the 15 subjects in the experimental group, 13 were male and 2 were female, while the control group composed of 9 males and 6 females. The average age was $40.86 \pm 13.07$ years for the experimental group and
$45.00 \pm 15.46$ years for the control group. As a result of the physical examination, taut band and referred pain were observed in both, the experimental and the control group. Localized twitching response was observed in all the 15 subjects of experimental group while 12 of the 15 subjects of the control group displayed the response. As a result of Fisher's Exact test and Mann-Whitney test carried out to examine the preliminary homogeneity between the 2 groups, both the groups were found to be homogeneous as there was no significant difference $(\mathrm{p}>0.05)$ (Table 1). As a result of Independent Samples t-Test carried out to examine the preliminary homogeneity of the preliminary assessment tools, preliminary measurement tools were found to be homogeneous as there was no significant difference $(\mathrm{p}>0.05)$ (Table 2).

Table 1. Demographic and Clinical Characteristics of Patients

\begin{tabular}{|c|c|c|c|c|}
\hline & & Control $(n=15)$ & ESWT $(n=15)$ & $\mathbf{p}$ \\
\hline \multirow[t]{2}{*}{ Sex } & Male & 9 & 13 & $0.215^{*}$ \\
\hline & Female & 6 & 2 & \\
\hline Age (years) & & $45.00 \pm 15.46$ & $40.86 \pm 13.07$ & $0.684^{\dagger}$ \\
\hline Taut band & $\begin{array}{l}\text { Positive } \\
\text { Negative }\end{array}$ & 15 & 15 & $1.000^{*}$ \\
\hline Local twitch response & $\begin{array}{l}\text { Positive } \\
\text { Negative }\end{array}$ & $\begin{array}{r}12 \\
3\end{array}$ & 15 & $0.224^{*}$ \\
\hline Referred pain & $\begin{array}{l}\text { Positive } \\
\text { Negative }\end{array}$ & 15 & 15 & $1.000 *$ \\
\hline
\end{tabular}

ESWT: Extracorporeal shock wave therapy

${ }^{*}$ Fisher's Exact test, ${ }^{\dagger}$ Mann-Whitney test, values are mean \pm standard deviation

Table 2. Pre-homogeneity Test of Preliminary Assessment

\begin{tabular}{lccc} 
& Control $(\mathbf{n}=\mathbf{1 5})$ & ESWT $(\mathbf{n}=\mathbf{1 5})$ & p \\
\hline McGill pain questionnaire & $24.40 \pm 6.02$ & $31.00 \pm 8.41$ & 0.166 \\
Visual analog scale & $7.20 \pm 1.30$ & $6.86 \pm 0.90$ & 0.599 \\
Pain rating scale & $25.20 \pm 7.95$ & $26.57 \pm 18.54$ & 0.881 \\
Pain threshold (lb/cm $\left.{ }^{2}\right)$ & $6.20 \pm 1.92$ & $6.86 \pm 1.35$ & 0.500 \\
Neck Flexion (55) & $52.00 \pm 5.70$ & $50.71 \pm 6.07$ & 0.719 \\
Neck Extension (40) & $38.00 \pm 4.47$ & $40.00 \pm 0.00$ & 0.374 \\
Neck Rt. Rotation (90) & $52.00 \pm 13.51$ & $50.00 \pm 10.80$ & 0.781 \\
Neck Lt. Rotation (90) & $55.00 \pm 6.12$ & $55.00 \pm 5.77$ & 0.923 \\
Neck Rt. Bending (40) & $34.00 \pm 8.22$ & $36.43 \pm 2.44$ & 0.470 \\
Neck Lt. Bending (40) & $32.00 \pm 9.08$ & $35.71 \pm 5.35$ & 0.391 \\
Neck Total ROM (355) & $263.00 \pm 31.34$ & $267.86 \pm 17.29$ & 0.736 \\
\hline
\end{tabular}

Independent Samples t-Test, Values are mean \pm standard deviation

ESWT: Extracorporeal shock wave therapy 


\section{The change in pain threshold}

As a result of Repeated Measure ANOVA on pain threshold, it was found that there was significant difference in accordance with groups ( $\mathrm{p}=0.045<0.05)$, time effect $(\mathrm{p}<0.001)$ and reciprocal action effect $(\mathrm{p}=0.001<0.01)$. As a result of contrast test on time, a significant difference was observed prior to commencement, following the 1st and the 3rd treatment, illustrating that the pain threshold began to increase after the 1st treatment. Effect of the group was found to be significant, resulting in higher pain threshold in the ESWT group in comparison to the TPI and TENS group. As a result of contrast test on the reciprocal action, there was significant difference prior to commencement, following the 1st and the 3rd treatment, illustrating that the treatment effect in the ESWT group was greater than the TPI and TENS group since the 1st treatment (Table 3).

\section{The changes in visual analog scale}

As a result of sphericity on VAS, it was found that sphericity assumption was satisfied ( $\mathrm{p}=0.071>0.05)$, and it was also found that although there was significant difference in VAS in accordance with groups $(\mathrm{p}=0.010<0.05)$ and time effect $(p<0.001)$, there was no reciprocal action effect $(\mathrm{p}=0.162>0.05)$. As a result of contrast test on time, there was significant difference in VAS prior to commencement, following the 1st and the 3rd treatment. Therefore, a significant reduction in VAS was noted following the treatment. Although there was significant difference in VAS between the groups, it was found that there was no reciprocal action effect. This signifies that treatment using ESWT is more effective than the treatment using TPI

Table 3. The Change in Pain Threshold and Visual Analog Scale

\begin{tabular}{|c|c|c|c|c|c|c|}
\hline & Before first therapy & After first therapy & After third therapy & & $\mathbf{F}$ & $\mathbf{p}$ \\
\hline \multicolumn{7}{|c|}{ Pain threshold $\left(\mathrm{lb} / \mathrm{cm}^{2}\right)$} \\
\hline ESWT & $6.86 \pm 1.35$ & $11.43 \pm 0.27$ & $12.57 \pm 0.72$ & Group (G) & 5.237 & 0.045 \\
\hline \multirow[t]{3}{*}{ Control } & $6.20 \pm 1.92$ & $8.80 \pm 0.48$ & $9.60 \pm 2.19$ & Time (T) & 67.217 & $<0.001$ \\
\hline & & & & $\mathrm{G} \times \mathrm{T}$ & 4.550 & 0.001 \\
\hline & Mauchly's Sphericity & test $\mathrm{W}=0.869(\mathrm{p}=0.53$ & & & & \\
\hline \multicolumn{7}{|c|}{ Visual analog scale } \\
\hline ESWT & $6.86 \pm 0.90$ & $2.86 \pm 0.90$ & $1.86 \pm 0.69$ & Group (G) & 9.940 & 0.010 \\
\hline \multirow[t]{2}{*}{ Control } & $7.20 \pm 1.30$ & $4.60 \pm 0.55$ & $2.80 \pm 0.84$ & Time $(\mathrm{T})$ & 94.360 & $<0.001$ \\
\hline & & & & $\mathrm{G} \times \mathrm{T}$ & 1.998 & 0.162 \\
\hline
\end{tabular}

Values are mean \pm standard deviation

ESWT: Extracorporeal shock wave therapy

Table 4. The Change in McGill Pain Questionnaire and Pain Rating Scale

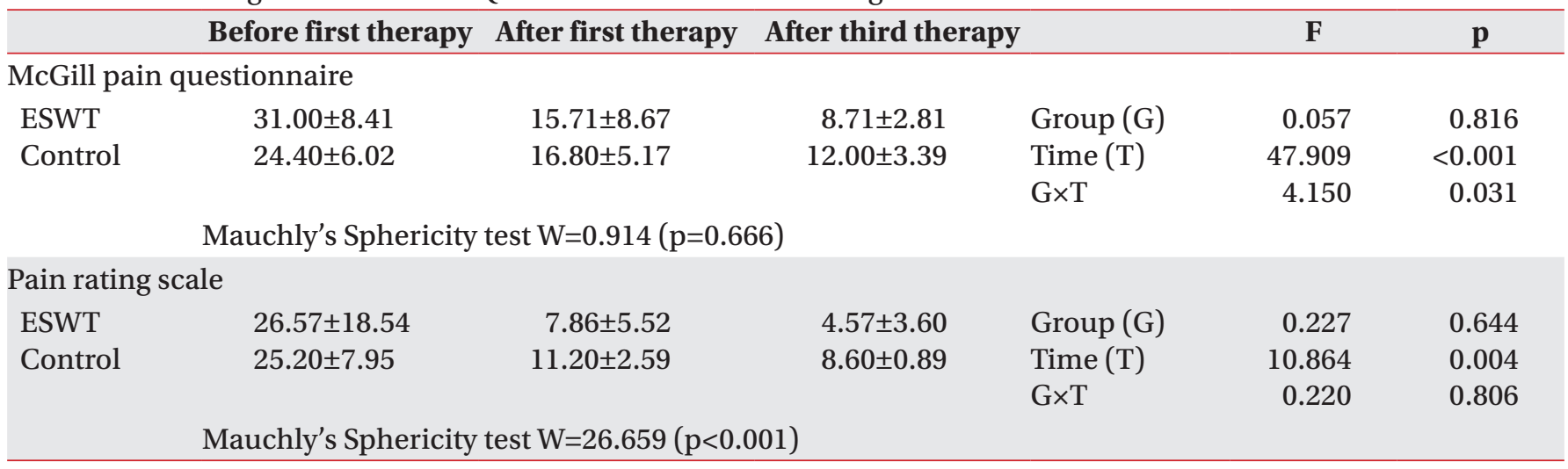

Values are mean \pm standard deviation

ESWT: Extracorporeal shock wave therapy 
and TENS since the VAS of the ESWT group was found to be lower than that of the TPI and TENS group (Table 3 ).

The changes in McGill pain questionnaire

Sphericity assumption was satisfied as a result of Repeated Measure ANOVA on McGillpain questionnaire $(p=0.666>0.05)$. Although there was no significant difference between the groups $(\mathrm{p}=0.816>0.05)$, time effect $(\mathrm{p}<0.001)$ and reciprocal action effect $(\mathrm{p}=0.031<0.05)$ was observed. As a result of contrast test on time, it was found that there was reduction following the 1st and the 3rd treatment in comparison to prior to commencement, thus illustrating that McGill pain questionnaire was significantly reduced as the treatment was carried out. There was significant difference in the results of contrast test on reciprocal action prior to commencement and following the 3rd treatment. This signifies that although the McGill pain questionnaire prior to commencement was found to be higher in the ESWT group, it was lower in the ESWT group following the 3rd treatment and that treatment using ESWT had greater effectiveness after the 3rd treatment (Table 4).

The changes in pain rating scale

Sphericity assumption was found to be unsatisfactory based on the result of sphericity on PRS $(\mathrm{p}<0.001)$. Based on the Repeated Measure ANOVA carried out by Wilks' Lambda, it was found that there was no significant difference between the groups $(\mathrm{p}=0.644>0.05)$ but also no reciprocal action effect $(\mathrm{p}=0.806>0.05)$, and only the time

Table 5. The Change in Neck Range of Motion

\begin{tabular}{|c|c|c|c|c|c|c|c|}
\hline & & Before first therapy & After first therapy & After third therapy & & $\mathbf{F}$ & $\mathbf{P}$ \\
\hline \multirow[t]{4}{*}{ Flexion } & ESWT & $50.71 \pm 6.08$ & $54.29 \pm 3.45$ & $54.29 \pm 3.45$ & Group (G) & 0.009 & 0.927 \\
\hline & Control & $52.00 \pm 5.70$ & $54.00 \pm 4.18$ & $54.00 \pm 4.18$ & Time $(\mathrm{T})$ & 7.824 & 0.003 \\
\hline & & & & & $\mathrm{G} \times \mathrm{T}$ & 0.622 & 0.547 \\
\hline & & Mauchly's Sphericity t & st $W=0.000(p=0.000$ & & & & \\
\hline \multirow[t]{4}{*}{ Extension } & ESWT & $40.00 \pm 0.00$ & $40.00 \pm 0.00$ & $40.00 \pm 0.00$ & Group (G) & 1.458 & 0.255 \\
\hline & Control & $38.00 \pm 4.47$ & $40.00 \pm 0.00$ & $40.00 \pm 0.00$ & Time $(\mathrm{T})$ & 1.458 & 0.256 \\
\hline & & & & & $\mathrm{G} \times \mathrm{T}$ & 1.458 & 0.256 \\
\hline & & Mauchly's Sphericity t & st $W=0.000(p=0.000$ & & & & \\
\hline \multirow[t]{4}{*}{ Right rotation } & ESWT & $50.00 \pm 10.80$ & $59.29 \pm 11.70$ & $62.86 \pm 4.88$ & Group (G) & 0.043 & 0.840 \\
\hline & Control & $52.00 \pm 13.51$ & $61.00 \pm 5.48$ & $62.00 \pm 4.47$ & Time (T) & 11.429 & $<0.001$ \\
\hline & & & & & $\mathrm{G} \times \mathrm{T}$ & 0.193 & 0.826 \\
\hline & & Mauchly's Sphericity t & est $W=0.880(p=0.563$ & & & & \\
\hline \multirow[t]{4}{*}{ Left rotation } & ESWT & $55.00 \pm 5.77$ & $65.00 \pm 6.46$ & $65.00 \pm 6.46$ & Group (G) & 0.496 & 0.186 \\
\hline & Control & $55.00 \pm 6.12$ & $61.00 \pm 5.48$ & $62.00 \pm 4.47$ & Time (T) & 29.842 & $<0.001$ \\
\hline & & & & & $\mathrm{G} \times \mathrm{T}$ & 2.211 & 0.166 \\
\hline & & Mauchly's Sphericity t & est $W=0.391(p=0.015$ & & & & \\
\hline \multirow[t]{4}{*}{ Right bending } & ESWT & $36.43 \pm 2.44$ & $40.00 \pm 0.00$ & $40.00 \pm 0.00$ & Group (G) & 0.859 & 0.376 \\
\hline & Control & $34.00 \pm 8.22$ & $38.00 \pm 4.47$ & $40.00 \pm 0.00$ & Time $(\mathrm{T})$ & 8.625 & 0.008 \\
\hline & & & & & $\mathrm{G} \times \mathrm{T}$ & 0.904 & 0.439 \\
\hline & & Mauchly's Sphericity t & est $W=0.241(p=0.002$ & & & & \\
\hline \multirow[t]{4}{*}{ Left bending } & ESWT & $35.71 \pm 5.35$ & $39.29 \pm 1.89$ & $40.00 \pm 0.00$ & Group (G) & 1.162 & 0.306 \\
\hline & Control & $32.00 \pm 9.08$ & $36.00 \pm 6.52$ & $40.00 \pm 0.00$ & Time $(\mathrm{T})$ & 4.911 & 0.036 \\
\hline & & & & & $\mathrm{G} \times \mathrm{T}$ & 0.825 & 0.469 \\
\hline & & Mauchly's Sphericity t & est $W=0.398(p=0.016$ & & & & \\
\hline Total & ESWT & $267.86 \pm 17.29$ & $297.86 \pm 12.86$ & $302.14 \pm 9.94$ & Group (G) & 0.379 & 0.552 \\
\hline \multirow[t]{3}{*}{ ROM } & Control & $263.00 \pm 31.35$ & $290.00 \pm 20.62$ & $298.00 \pm 7.58$ & Time $(\mathrm{T})$ & 51.023 & $<0.001$ \\
\hline & & & & & $\mathrm{G} \times \mathrm{T}$ & 0.474 & 0.637 \\
\hline & & Mauchly's Sphericity t & est $W=0.369(p=0.011$ & & & & \\
\hline
\end{tabular}

Values are mean \pm standard deviation

ESWT: Extracorporeal shock wave therapy 
( $\mathrm{p}=0.004<0.01)$ effect was found to be significant. As a result of contrast test on time, significant difference prior to commencement and following the 1st and the 3rd treatment was observed, illustrating that PRS was reduced significantly since the 1st treatment (Table 4).

\section{The changes in neck range of motion}

As a result of the Repeated Measure ANOVA carried out on neck range of motion, there was no significant difference between the groups ( $p>0.05)$ but also no reciprocal action effect $(p>0.05)$ in all the category, and, in all the categories excluding extension, time $(\mathrm{p}<0.05)$ effect was found to be significant. Therefore, it was found that there was effectiveness of treatment on both the ESWT group and TPI and TENS group in terms of neck range of motion (Table 5).

\section{Final response assessment}

As a result of measurement of Roles and Maudsley score, experimental group had 6 subjects with rating of excellent and 9 subject with rating of good among total of 15 subjects while control group had 3 subjects with rating of excellent, 9 subjects with rating of good and 3 subjects with rating of acceptable among the total of 15 subjects. There was no significant difference between the groups $(\mathrm{p}=0.233>0.05)$.

As a result of measurement in the final response assessment, experimental group had 10 subjects with rating of excellent and 5 subjects with rating of good among total of 15 subjects while control group had 6 subjects with rating of excellent and 9 subjects with rating of good among total of 15 subjects. There was no significant difference between the groups $(p=0.272>0.05)$.

\section{Gender difference on the final assessment}

As a result of confirmation of the differences between the gender in the final assessment in order to determine the differences in the results of treatment in the 2 groups due to gender ratio, no significant gender difference ( $>0.05$ ) was observed (Table 6).

\section{DISCUSSION}

The ESWT was first applied in Germany in 1996 and following 5 diseases to which ESWT can be applied clinically were proposed: (1) calcific tendonitis, (2) lateral epicondylitis, (3) medial epicondylitis, (4) plantar fasciitis, and (5) pseudoarthrosis. ${ }^{2}$ Typical characteristic of the shock wave generated in ESWT is that pressure reaches $100 \mathrm{MPa}$ or 1,000 times that of atmospheric pressure during short period of several nanoseconds, which then gradually falls to the normal level prior to turning into negative pressure. The negative pressure equivalent to approximately $10 \%$ of the size of the maximum pressure generated is the characteristic of the shock wave and cavitational effect is generated through this characteristic feature. Shock wave used for medical purposes includes extracorporeal shock wave lithotripsy (ESWL) and ESWT, which are used by focusing the shock wave generated outside the body on the target area in patients with urolithiasis or orthopedic diseases. $^{3}$

The ESWT equipment currently used in clinical setting

Table 6. Independent Samples t-Test of Final Assessment between Male and Female Subjects

\begin{tabular}{|lccc}
\hline & Male $(\mathbf{n}=\mathbf{2 2})$ & Female $(\mathbf{n}=\mathbf{8})$ & $\mathbf{p}$ \\
\hline McGill pain questionnaire & $9.22 \pm 2.48$ & $12.67 \pm 4.93$ & 0.130 \\
\hline Visual analog scale & $2.22 \pm 0.83$ & $2.33 \pm 1.15$ & 0.858 \\
\hline Pain rating scale & $5.44 \pm 3.57$ & $8.67 \pm 1.15$ & 0.166 \\
\hline Pain threshold (Ib/cm $\left.{ }^{2}\right)$ & $11.89 \pm 2.02$ & $9.67 \pm 3.05$ & 0.173 \\
\hline Neck Flexion (55) & $54.44 \pm 3.90$ & $53.33 \pm 2.88$ & 0.664 \\
\hline Neck Extension (40) & $40.00 \pm 0.00$ & $40.00 \pm 0.00$ & \\
\hline Neck Rt. Rotation (90) & $62.22 \pm 4.41$ & $63.33 \pm 5.77$ & 0.731 \\
\hline Neck Lt. Rotation (90) & $63.89 \pm 6.00$ & $63.33 \pm 5.77$ & 0.892 \\
\hline Neck Rt. Bending (40) & $40.00 \pm 0.00$ & $40.00 \pm 0.00$ & \\
Neck Lt. Bending (40) & $40.00 \pm 0.00$ & $40.00 \pm 0.00$ & 0.931 \\
\hline Neck Total ROM (355) & $300.56 \pm 9.50$ & $300.00 \pm 8.66$ & \\
\hline
\end{tabular}

Values are mean \pm standard deviation 
is divided into radial and focused methods in accordance with the manner in which the shock wave reaches the target. There are 3 methods of generating focusedtype shock wave, namely, piezoelectric, electromagnetic and electrohydraulic methods. Shock wave is generated by using the principle in which electricity is converted into shock wave through quick physical movement of electricity in a liquid medium. Each of the equipment uses charged condenser with different voltage from each other, and conversion into shock wave is achieved as electricity becomes rapidly discharged in acoustic transducer. $^{3}$ ESWT can be classified in accordance with the level of energy flux density (EFD) into as low energy with EFD range of $0.08-0.27 \mathrm{~mJ} / \mathrm{mm}^{2}$, intermediate energy with EFD range of $0.28-0.59 \mathrm{~mJ} / \mathrm{mm}^{2}$, and high energy with EFD of more than $0.6 \mathrm{~mJ} / \mathrm{mm}^{2}$. In addition, although another standard for classification into low energy for EFD of less than $0.12 \mathrm{~mJ} / \mathrm{mm}^{2}$ and high energy for EFD of more than $0.12 \mathrm{~mJ} / \mathrm{mm}^{2}$ has been presented, ${ }^{4}$ there is no definitively unified standard yet. Electrohydraulic format of low energy flux density used in this study in which shock wave is generated in the typical format of pressurized wavelength that rapidly increases within extremely short period of time and then decreases gradually is known to have little side effects and excellent effectiveness as per the results of laboratory research, ${ }^{3,5}$ and low energy extracorporeal shock wave therapy, in comparison to treatment using high energy, requires no localized anesthesia at the time of treatment and is known to prevent the interference of recovery of the damaged tissues and rupture of tissues that could occur with high energy extracorporeal shock wave therapy. ${ }^{3,6}$ In addition, by using low energy, it is possible to prevent the phenomenon of lowering of the level of adaptation of the patients or giving up of the treatment in the middle by the patients, due to the pain caused by the treatment itself that occurs when high energy shock wave is used. However, histological reaction on extracorporeal shock wave is known to be dose-dependent on the total energy delivered (Total Effectiveness Energy=EFD $\left(\mathrm{mJ} / \mathrm{mm}^{2}\right) \times \mathrm{mm}^{2} \times$ number $)$ $(\mathrm{mJ})^{3,7}$ and, low-energy treatment has the disadvantage of having to perform treatment several times in order to maintain the total energy delivered to the area to be treated at the level similar to that of high energy extracorporeal shock wave.

Until now, there is no guideline that clearly defines the number of and interval for execution of ESWT. In the study by Jung et al., ${ }^{8}$ in which low energy shock wave treatment for chronic epicondylitis of elbow joint was carried out, approximately 2,000 shock waves with low EFD range of $0.06-0.12 \mathrm{~mJ} / \mathrm{mm}^{2}$ were delivered in accordance with the pain tolerance of the patient during each treatment for total of 3 times with a week's interval between treatments, and, in the study by Kim et al. ${ }^{9}$ on the effectiveness of extracorporeal shock wave therapy on plantar fasciitis patients, 1,200 shock waves with low EFD of $0.24 \mathrm{~mJ} / \mathrm{mm}^{2}$ were delivered for total of 3 times with a week's interval between the treatments. In this study, subjects were given total of 1,500 shock waves for each treatment at the rate of 240 waves, each with low energy flux density (EFD) of $0.10 \mathrm{~mJ} / \mathrm{mm}^{2}$ per minute by using for total of 3 times with interval of a week between the treatments (total of 4,500 shock waves). When shock wave was applied to the accurate area at the time of treatment, it was possible to confirm that induction of pain and referred pain as well as muscular twitching response occurred in the entire experimental group.

In general, it is known that the effect of extracorporeal shock wave in living tissues induces characteristic changes within the cells due to conversion of the mechanical signal into biochemical or molecular biologic signal (Mechanotransduction). ${ }^{10}$ According to the available knowledge, although the mechanisms of ESWT are not clear, several hypothesis have been discussed on the principles of cellular and molecular biological effects. According to Zimmermann et al., ${ }^{10}$ ESWT improves blood circulation in capillary blood vessels and reduces the tension and stiffness of muscles along with the reduction in pain by inducing interference of flow of excessive stimulation of nociceptors and stimulation of nerves. In addition, the study carried out by Hausdorf et al. ${ }^{11,12}$ states that ESWT reduces pain in the tissues of musculoskeletal system through selective destruction of nonmyelinated fibers and is effective in reducing the level of substance $\mathrm{P}$ in the target tissue as well as reducing the synthesis of substance $\mathrm{P}$ in dorsal root ganglia. According to Wang et al., ${ }^{13}$ ESWT is known to be effective in acceleration of perfusion in the ischemic tissues (myocardium and skin flap) and stimulation of generation of new blood vessels, and according to Davis et al., ${ }^{14}$ it is effective in recovering the areas of ischemic skin flap and increasing the perfusion of tissues through reduction effect on inflammation. According to De Sanctis et al., ${ }^{15}$ ESWT is effective in leading to improvement of circulation in capillary blood 
vessels in the chronic ischemic areas of lower limbs when it is performed on people and according to Fukumoto et al., ${ }^{16}$ it is effective in improving the perfusion of myocardium in patients with severe diseases of coronary artery. As per the study by Sparsa et al., ${ }^{17}$ ESWT has been reported to reduce pain and calcification and accelerate reepithelization in CREST syndrome and chronic leg ulcer.

In a study by Muller-Ehrenberg and Licht, ${ }^{18}$ focusedtype extracorporeal shock wave therapy was carried out on 30 patients with myofascial pain syndrome, pain and typical referred pain were induced in $95 \%$ of the subjects while ESWT was performed; in the assessment following application of shock wave treatment with 800-1,000 shock waves with low energy flux density in the range of 0.04 $0.26 \mathrm{~mJ} / \mathrm{mm}^{2}$ for each treatment at the interval of a week or 2 weeks by dividing the subjects into 5 levels in accordance with the intensity of pain and sensitivity of the patients for total of 7.3 times on the average (minimum of 2 times to maximum of 16 times) a reduction in VAS from 3.6 prior to treatment to 1.7 following treatment during the rest, and from 7.4 prior to treatment to 3.4 following treatment during activities was observed. Although the clear mechanism of effectiveness of ESWT could not be explained in the above study, it was explained that there would be improvement in ischemia due to improvement in vicious cycle of localized contraction of muscles and generation of new blood vessels, and reduction in the pain due to reduction in the nonmyelinated fibers in myofascial pain syndrome. In addition, it was explained that performing ESWT could be helpful in diagnosis of myofascial pain syndrome by inducing generation of pain and referred pain along with the reduction in pain, which is a therapeutic effect.

In this study, when the mechanisms through which the ESWT was effective on myofascial pain syndrome are considered, abnormal shortening of muscle occurs due to increase in excessive discharge of acetylcholine into the neuromuscular junction as one of the factor of causing myofascial trigger points. This does not occur in all the muscle fibers but rather only in some of the sarcomere histologically. Such an abnormal shortening induces the localized ischemia and increases the metabolism of the shortened areas, and causes energy crisis. Various pain inducing substances (prostaglandin, bradykinin, substance $\mathrm{P}, \mathrm{CGRP}, \mathrm{K}^{+}$, serotonin and histamine, etc.) are secreted due to energy crisis, which eventually induces localized pain by supersensitization of nocicep- tors of muscles. ${ }^{19-21}$ It can be contemplated that due to the execution of ESWT, reduction in the level of muscular tension and improvement of localized ischemia in the areas of abnormal shortening of the muscles can be achieved, which will in turn inhibit increase in metabolism and occurrence of energy crisis, reduce secretion of various pain inducing substances, and inhibit the induction of pain due to excessive stimulation of nociceptors of muscles and selective destruction of nonmyelinated fibers. Moreover, referred pain that occurs in myofascial pain syndrome is due to easy induction of central sensitization due to lowering of the activation threshold of nociceptors of peripheral muscles (Central hyperexcitability theory). ${ }^{22}$ Therefore, it can be thought that execution of ESWT could inhibit occurrence of referred pain by inhibiting excessive excitement of nerve cells due to reduction in the synthesis of substance $P$ at the dorsal root ganglia while at the same time preventing central sensitization by inhibiting nociceptors of peripheral muscles.

In order to diagnose myofascial pain syndrome, detailed past history, diagnostic findings through physical examination and confirmative findings are necessary. As a confirmative finding, localized twitching response and typical referred pain need to be confirmed at the time of application of needle or pressurization. In this study, it was possible to confirm that localized muscular twitching reaction and typical referred pain were induced when shock wave was applied on accurate location in the group that underwent ESWT.

At present, diagnosis of myofascial pain syndrome is made on the basis of findings of physical examination as there is no available laboratory test or examination tool that is generally established for confirmed diagnosis. Measurement of pain threshold on the pressure by using algometry at the areas that correspond to the point of induction of pain can be helpful in diagnosis as the extent of pain can be expressed with respect to objective value. ${ }^{1}$ In the event of measuring the pain threshold, the pain threshold at the area with point of induction of pain would be significantly lower than that of normal tissues. ${ }^{23}$ According to the study by Kim et al., ${ }^{24}$ increase in all the pain thresholds was observed when TENS and intramuscular electrical stimulation (IMES) were carried out on patients with myofascial pain syndrome. In this study, increase in the pain threshold was also observed in all the subjects in the groups that underwent ESWT, and TPI and TENS. Moreover, since the 1st treatment, statisti- 
cally more significant increase in the pain threshold was observed in the ESWT group in comparison to the TPI and TENS group thereby illustrating the effectiveness of ESWT.

Limitations of this study include the point that treatment has been standardized due to lack of definitive guidelines on the intensity, interval and frequency of the stimulation for ESWT for diseases of musculoskeletal system and the most important limitation is that explanations on the principles and mechanisms of the effectiveness of ESWT are provided on the basis of hypothesis and inferences based on the past researches. Therefore, it is deemed that additional cytohistological and molecular biologic researches are needed in the future.

\section{CONCLUSION}

In this study, it was found that ESWT is as effective in causing reduction in pain and improvement in neck range of motion as TPI and TENS in patients with myofascial pain syndrome in trapezius muscle. In addition, execution of ESWT is deemed to be helpful in diagnosing myofascial pain syndrome as it would enable confirmation of occurrence of referred pain and muscular twitching response, which are the standards for the diagnosis of myofascial pain syndrome.

The ESWT is one of the novel treatment methods with its wide range of clinical application, which are gradually expanding for the purpose of treatment of diseases of musculoskeletal system. It is being applied to diverse range of areas due to the usefulness in clinical application since it is non-invasive, can be repeated and carried out in a relative safer manner. However, researches on its mechanism are still inadequate and standardized treatment guideline is yet to be established in order to produce the optimal results. Therefore, continuous efforts to establish the most effective treatment guidelines are needed in the future, and, if relationship between the mechanism and therapeutic adaptability can be investigated more clearly and definitively, it is expected to play more important role in the area of rehabilitative therapy.

\section{REFERENCES}

1. Han TR, Bang MS. Myofascial pain. In: Kang YK, editor. Rehabilitation medicine, 3rd ed, Seoul: Koonja, 2008, 887-896
2. McClure S, Weinberger T. Extracorporeal shock wave therapy: clinical applications and regulation. Clin Tech Equine Pract 2003; 2: 358-367

3. McClure S, Dorfmuller C. Extracorporeal shock wave therapy: theory and equipment. Clin Tech Equine Pract 2003; 2: 348-357

4. Speed CA. Extracorporeal shock-wave therapy in the management of chronic soft-tissue conditions. J Bone Joint Surg Br 2004; 86: 165-171

5. Ogden JA, Alvarez RG, Levitt RL, Johnson JE, Marlow ME. Electrohydraulic high-energy shock-wave treatment for chronic plantar fasciitis. J Bone Joint Surg Am 2004; 86: 2216-2228

6. Rompe JD, Meurer A, Nafe B, Hoffmann A, Gerdesmeyer L. Repetitive low-energy shock wave application without local anesthesia is more efficient than repetitive low-energy shock wave application with local anesthesia in the treatment of chronic plantar fasciitis. J Orthop Res 2005; 23: 931-941

7. Rompe JD, Kirkpatrick CJ, Kullmer K, Schwitalle M, Krischek O. Dose-related effects of shock waves on rabbit tendo achillis. A sonographic and histological study. J Bone Joint Surg Br 1998; 80: 546-552

8. Jung KH, Hwang JH, Chang HJ, Yoon YC, Park MJ, Yoo JC, Park WH. Low-energy extracorporeal shock wave therapy on chronic epicondylitis of the elbow: clinical and sonography study. J Korean Acad Rehab Med 2009; 33: 77-83

9. Kim SB, Lee KW, Lee JH, Kim YD, Yoon KS, Joe YL. The effect of extracorporeal shock wave therapy in plantar fasciitis. J Korean Acad Rehab Med 2009; 33: 333-338

10. Zimmermann R, Cumpanas A, Miclea F, Janetschek G. Extracorporeal shock wave therapy for the treatment of chronic pelvic pain syndrome in males: arandomised, double-blind, placebo-controlled study. Eur Urol 2009; 56: 418-424

11. Hausdorf J, Lemmens MA, Heck KD, Grolms N, Korr H, Kertschanska S, Steinbusch HW, Schmitz C, Maier M. Selective loss of unmyelinated nerve fibers after extracorporeal shockwave application to the musculoskeletal system. Neuroscience 2008; 155: 138-144

12. Hausdorf J, Lemmens MA, Kaplan S, Marangoz C, Milz S, Odaci E, Korr H, Schmitz C, Maier M. Extracorporeal shock wave application to the distal femur of rabbits diminishes the number of neurons immunoreactive for substance P in dorsal root ganglia L5. 
Brain Res 2008; 1207: 96-101

13. Wang CJ, Wang FS, Yang KD, Weng LH, Hsu CC, Huang CS, Yang LC. Shock wave therapy induces neovascularization at the tendon-bone junction. A study in rabbits. J Orthop Res 2003; 21: 984-989

14. Davis TA, Stojadinovic A, Amare K, Anam M, Naik S, Peoples GE, Tadaki D, Elster EA. Extracorporeal shock wave therapy suppresses the early proinflammatory immune response to a severe cutaneous burn injury. Int Wound J 2009; 6: 11-21

15. De Sanctis MT, Belcaro G, Nicolaides AN, Cesarone MR, Incandela L, Marlinghaus E, Griffin M, Capodanno S, Ciccarelli R. Effects of shock waves on the microcirculation in critical limb ischemia (CLI) (8week study). Angiology 2000; 51: S69-78

16. Fukumoto Y, Ito A, Uwatoku T, Matoba T, Kishi T, Tanaka H, Takeshita A, Sunagawa K, Shimokawa H. Extracorporeal cardiac shock wave therapy ameliorates myocardial ischemia in patients with severe coronary artery disease. Coron Artery Dis 2006; 17: 6370

17. Sparsa A, Lesaux N, Kessler E, Bennetblanc JM, Nlaise S, Lebrun-Ly V, Colombeau P, Vidal E, Bedane C. Treatment of cutaneous calcinosis in CREST syndrome by extracorporeal shock wave lithotripsy. J Am Acad Dermatol 2005; 53: S263-265

18. Muller-Ehrenberg H, Licht G. Diagnosis and therapy of myofascial pain syndrome with focused shock waves (ESWT). Med Orthop Tech 2005; 5: 1-6

19. McNulty WH, Gevirtz RN, Hubbard DR, Berkoff GM. Needle electromyographic evaluation of trigger point response to a psychological stressor. Psychophysiology 1994; 31: 313-316

20. Chen JT, Chen SM, Kuan TS, Chung KC, Hong CZ. Phentolamine effect on the spontaneous electrical activity of active loci in a myofascial trigger spot of rabbit skeletal muscle. Arch Phys Med Rehabil 1998; 79: 790-794

21. Lewis C, Gevirtz R, Hubbard D. Needle trigger point and surface frontal EMG measurement of psychophysiological responses in tension type headache patients. Biofeedback Self Regul 1994; 19: 274-275

22. Giamberardino MA, Costantini R, Affaitati G, Fabrizio A, Lapenna D, Tafuri E, Mezzetti A. Viscero-visceral hyperalgesia: characterization in different clinical models. Pain 2010; 151: 307-322

23. Vecchiet L, Giamberardino MA, Dragani L, de Bigontina P, Albe-Fessard D. Latent myofascial trigger points: changes in muscular and subcutaneous pain thresholds at trigger point and target level. J Manual Medicine 1990; 5: 151-154

24. Kim YJ, Lee YH, Kim IS, Kim SH, Auh KB, Yu MG. Effects of electrical stimulation of transcutaneous electrical nerve and acupuncture stimulation in patients with myofascial pain syndrome. J Korean Acad Rehab Med 2007; 31: 25-29 